\title{
Intergroup Rhabdomyosarcoma Group IV
}

National Cancer Institute

\section{Source}

National Cancer Institute. Intergroup Rhabdomyosarcoma Group IV. NCI Thesaurus.

Code C148022.

Distant metastasis. 